\title{
Seric Calcium and Magnesium in Normal and Pre Eclamptic Pregnant Women: A Case-Control Study in Kinshasa, D R Congo
}

\author{
Pascal Ngoy Wakumilua1, Donatien Kayembe Nzongola-Nkasu², Jean Pierre Elongi Moyene ${ }^{3 *}$, \\ Dophie Tshibuela Beya ${ }^{2}$, Mamy Ngole Zita², Jeremie Muwonga Masidi², Mireille Nganga Nkanga², \\ Guelord Mukiapini Luzolo², Daddy Kabamba Numbi ${ }^{2}$
}

\begin{abstract}
${ }^{1}$ Département de Sciences de la Santé/Faculté de Sciences/Université Pédagogique Nationale, Kinshasa, RD Congo
${ }^{2}$ Département de Biologie Médicale, Service de Biologie Cliniques, Cliniques Universitaires de Kinshasa, Kinshasa, RD Congo

${ }^{3}$ Département de Gynécologie-Obstétrique, Hôpital Général de Référence de Kinshasa, Kinshasa, RD Congo

Email: ngoywakumilwa@yahoo.fr, kayembe.donatien@gmail.com, *elongi2002@yahoo.fr, dophiebeya@gmail.com, mmyngole@gmail.com,pmuwonga@hotmail.commnganga2002@yahoo.fr, mireille.nganga@unikin.ac.cd,

mukiapiniguelord@gmail.com, dagsdaddy23@gmail.com
\end{abstract}

\begin{abstract}
How to cite this paper: Wakumilua, P.N., Nzongola-Nkasu, D.K., Moyene, J.P.E., Beya, D.T., Zita, M.N., Masidi, J.M., Nkanga, M.N., Luzolo, G.M. and Numbi, D.K. (2018) Seric Calcium and Magnesium in Normal and Pre Eclamptic Pregnant Women: A CaseControl Study in Kinshasa, D R Congo. Open Journal of Obstetrics and Gynecology, 8, 408-415.
\end{abstract}

https://doi.org/10.4236/ojog.2018.84046

Received: January 6, 2018

Accepted: April 22, 2018

Published: April 25, 2018

Copyright () 2018 by authors and Scientific Research Publishing Inc. This work is licensed under the Creative Commons Attribution International License (CC BY 4.0).

http://creativecommons.org/licenses/by/4.0/ (c) (i) Open Access

\begin{abstract}
Goal: The present study aimed to determine the profile of seric calcium and magnesium in pre-eclamptic and eclamptic pregnant women of Kinshasa province in the Democratic Republic of Congo where preeclampsia is characterized not only by a high incidence, but also by a seasonal variation probably related to nutritional intake. Study Design: This is a case-control study that took place during the period from September 2014 to March 2015 in four quaternary and tertiary maternity hospitals in Kinshasa. A total of 113 healthy pregnant women (controls) and 112 pre-eclamptic and eclamptic pregnant women (cases) were included in this study. Seric calcium and magnesium were measured in all these gravidas by the principle of spectrophotometry with a HUMALYSER Primus semi-automaton. Results: The mean age of those gravidas was $26.8 \pm 6.3$ years (26.7 vs $26.9, p=0.11$ ). The majority of these gravidas were primiparous. The mean gestational age in both groups was $31.35 \pm 0.9$ weeks ( 32.1 vs $30.6, p=0.21$ ). The average seric calcium value was $4.47 \pm 0.23 \mathrm{mEq} / \mathrm{L}$ in healthy pregnant women compared to $3.80 \pm 0.71$ $\mathrm{mEq} / \mathrm{l}$ in pre-eclamptics $(P<0.001)$. The mean of seric magnesium was $1.56 \pm$ $0.15 \mathrm{mg} / \mathrm{dL}$ in healthy pregnant women compared to $1.20 \pm 0.41 \mathrm{mg} / \mathrm{dL}$ in pre eclamptics $(P<0.001)$. Seric calcium and magnesium values were low in the pre-eclamptic group and lower in the eclamptic group $(P<0.001)$. Conclusion: This study establishes a relationship between the low concentration of seric calcium and magnesium with pre-eclampsia and eclampsia, which could
\end{abstract}


be one of the determinants of the high prevalence and seasonality of the disease in Kinshasa.

\section{Keywords}

Seric, Calcium, Magnesium, Preeclampsia, Kinshasa

\section{Introduction}

Preeclampsia affects $3 \%-10 \%$ of pregnancies and is responsible for a large maternal and fetal morbidity and mortality worldwide [1]. Although the oxidative stress generated by hypoxia is a major component in the set of mechanisms that contribute to the occurrence of this condition and associated complications, studies in the most affected regions in Africa and Asia have established a relationship between low intakes of certain micronutrients and the occurrence of the disease, which would probably be one of the determinants of the high prevalence and seasonality of the disease in these regions of the world [2]-[7].

Some of these studies indicate that nutritional deficiency of calcium and magnesium is associated with a high risk of preeclampsia and its complications [8]. On the one hand hypocalcemia and hypomagnesemia lead to spasms and increase in vascular resistance that lead to arterial hypertension. On the other hand, by stimulating the $\mathrm{N}$-methyl-D-aspartate receptors, hypoxia promotes the penetration of calcium into the cellule reversing the intracellular $\mathrm{Mg} / \mathrm{Ca}$ ratio, resulting in significant cellular alterations with consequent release of oxygen free radicals, generalized endothelial dysfunction and the release of certain neuromediators causing preeclampsia and eclampsia [9] [10].

Thus, fluctuations in blood levels of calcium and magnesium seem to play a significant role in the pathophysiology of preeclampsia and its complications alongside hypoxia.

The present study aims to determine the profile of seric calcium and magnesium in pre-eclamptic and eclamptic gravidas in the city of Kinshasa province, one of the most populated urban areas in sub-Saharan Africa where not only the incidence of preeclampsia is high, but it also has seasonal variation [11], probably related to nutritional intakes of micronutrients, particularly calcium and magnesium.

\section{Material and Methods}

This is a case-control study that took place during the period from September 2014 to March 2015 in four maternity hospitals at the quaternary and tertiary level in the city of Kinshasa Province (DR Congo), namely the university clinic of Kinshasa, the Kinshasa General Hospital, the St. Joseph Hospital and the Mother and Children Center of Bumbu.

The size of our sample was calculated from the following formula: $n=z^{2}$ 
$(\mathrm{pq}) / \mathrm{e}^{2}$, where $\mathrm{n}=$ sample size, $\mathrm{z}=$ level of confidence according to the reduced normal centered law (for a 95\% confidence level, $\mathrm{z}=1.96 ; p=$ estimated proportion of the population with the characteristic; $\mathrm{q}=100-p, \mathrm{e}=$ acceptable margin of error.

A total of 113 healthy pregnant women (controls) and 112 pre-eclamptic and eclamptic pregnant women (cases) were included in this study. These gravidas were recruited from units specialized in the management of hypertensive disorders of pregnancy (for cases) or during prenatal consultations (for controls). The study protocol was approved by the Ethic Committee of the Public Health School/University of Kinshasa. Participation in the study was voluntary after informed consent from the pregnant woman herself or her family in case of eclamptic coma.

Preeclampsia and eclampsia were defined according to the criteria set by the High Blood Pressure Education Program (NHBPEP) by a blood pressure greater than $140 / 90 \mathrm{mmHg}$ after 20th week of gestation, associated with a significant proteinuria greater than $300 \mathrm{mg} / 24$ hours [12].

Excluded from this study were women with multiple pregnancies, those taking diuretic medication, those who received magnesium sulphate and those with renal insufficiency, diabetes, anemia, cardiovascular disease, malabsorption

Seric calcium and magnesemium were measured in all these gravidas by the principle of spectrophotometry with a HUMALYSER Primus semi-automaton.

The reference values for these assays are 4.5 to $5.5 \mathrm{mEq} / \mathrm{L}$ for seric calcium, and 1.6 to $2.6 \mathrm{mg} / \mathrm{dl}$ for magnesium.

Descriptive statistics calculations (frequency, mean, median) were performed and the Mann-Whitney test was used to compare the values obtained in the two groups, with a significance level of 0.01 .

\section{Results}

A total of 225 pregnant women were included in this study, including 113 healthy pregnant women (controls) and 112 pregnant patients (96 pre-eclamptic and 16 eclamptic women)

The average age of gravidas was $26.8 \pm 6.3$ years ( 26.7 vs $26.9, p=0.11)$. The majority of these gravidas were primiparous (58/113 healthy pregnants Vs $57 / 112$ preeclamptics, $p=0.23$ ). The mean gestational age in both groups was $31.35 \pm 0.9$ weeks ( 32.1 Vs $30.6, p=0.21$ ).

The values for seric calcium and magnesium are given in Table 1 . The average seric calcium value was $4.47 \pm 0.23 \mathrm{mEq} / \mathrm{L}$ in healthy pregnant women compared to $3.80 \pm 0.71 \mathrm{mEq} / \mathrm{L}$ in patients (pre-eclamptic and eclamptic) $(P<$ $0.001)$. Mean magnesium level was $1.56 \pm 0.15 \mathrm{mg} / \mathrm{dL}$ in the control group compared to $1.20 \pm 0.41 \mathrm{mg} / \mathrm{dL}$ in the case group $(P<0.001)$.

The comparison of mean seric calcium and magnesium values in pre-eclamptic and eclamptic pregnancies is given in Table 2 . The average serum calcium value was $3.70 \pm 0.56 \mathrm{mEq} / \mathrm{l}$ in pre-eclamptic pregnant women compared to $3.20 \pm 0.41 \mathrm{mEq} / \mathrm{l}$ for eclamptic $(P<0.001)$; that of seric magnesemium 
Table 1. Comparison of the means of calcemia and magnesemia between the groups of healthy and pre eclamptic pregnant.

\begin{tabular}{cccc}
\hline & $\begin{array}{c}\text { GESTANT } \\
\text { HEALTHY }\end{array}$ & $\begin{array}{c}\text { GESTANT PRE } \\
\text { ECLAMPTIC }\end{array}$ & $\boldsymbol{P}$ Value \\
\hline CALCEMIA (mEq/l) & $4.47 \pm 0.23$ & $3.80 \pm 0.71$ & $<0.001$ \\
MAGNESEMIA (mg/dl) & $1.56 \pm 0.15$ & $1.20 \pm 0.41$ & $<0.001$ \\
\hline
\end{tabular}

Table 2. Comparison of mean values of serum calcium and magnesium between pre-eclamptic and pre-eclamptic pregnant.

\begin{tabular}{cccc}
\hline & $\begin{array}{c}\text { PRE ECLAMPTIC } \\
\text { PREGNANT }\end{array}$ & $\begin{array}{c}\text { ECLAMPTIC } \\
\text { PREGNANT }\end{array}$ & $\boldsymbol{P}$ Value \\
\hline CALCEMIA (mEq/l) & $3.70 \pm 0.56$ & $3.20 \pm 0.41$ & $<0.001$ \\
MAGNESEMIA (mg/dl) & $1.25 \pm 0.36$ & $1.15 \pm 0.46$ & $<0.001$ \\
\hline
\end{tabular}

was $1.25 \pm 0.36 \mathrm{mg} / \mathrm{dl}$ in pre-eclamptic pregnant women compared to $1.15 \pm 0.46$ eclamptic women $(P<0.001)$.

The comparison of values of seric calcium and magnesium between the group of healthy pregnant, pre-eclamptic and eclamptic women is given in Table 3. There is a very significant difference of the values obtained in these 3 subgroups: the values obtained decreased going from healthy pregnant groups to pre-eclamptics and eclamptics $(P<0.001)$.

\section{Discussion}

The pathophysiology of pre-eclampsia is still less well known today. Of all the hypotheses put forward to explain the occurrence of this condition, it seems that the oxidative stress generated by the metabolism and homeostasis disorder of certain minerals and vitamins play a significant role by the fact that it is responsible for endothelial dysfunction at the origin of clinical manifestations of the disease especially, the occurrence of arterial hypertension and its severity. Studies show that nutritional deficiencies are common during pregnancy and pregnant women in developing countries have been reported to consume diets that are low in minerals and vitamins [13]. Dietary deficiencies of calcium and magnesium during pregnancy have been implicated in preeclampsia, eclampsia, preterm birth and intrauterine growth retardation [14]. Several epidemiological studies in developing nations indicate an association between reduced calcium intake and preeclampsia. These observations led to the hypothesis that the incidence of preeclampsia can be reduced in populations of low calcium intake by calcium supplementation [15]. Magnesium has been known as an essential cofactor for many enzyme systems. It also plays an important role in neurochemical transmission and peripheral vasodilatation [16]. Magnesium supplementation during pregnancy may be able to reduce fetal growth retardation and preeclampsia and increase birth weight [17]. The modification of calcium and magnesium metabolism during pregnancy could be a potential cause of pre-eclampsia. 
Table 3. Comparison of mean values of serum calcium and magnesium between the three different groups of pregnant women (healthy, pre-eclamptic and eclamptic).

\begin{tabular}{ccccc}
\hline & $\begin{array}{c}\text { GESTANT } \\
\text { HEALTHY }\end{array}$ & $\begin{array}{c}\text { PRE ECLAMPTIC } \\
\text { GESTANT }\end{array}$ & $\begin{array}{c}\text { ECLAMPTIC } \\
\text { GESTANT }\end{array}$ & P Value \\
\hline CALCEMIA (mEq/l) & $4.47 \pm 0.23$ & $3.70 \pm 0.56$ & $3.20 \pm 0.41$ & $<0.001$ \\
MAGNESEMIA (mg/dl) & $1.56 \pm 0.15$ & $1.25 \pm 0.36$ & $1.15 \pm 0.46$ & $<0.001$ \\
\hline
\end{tabular}

It has been demonstrated by numerous studies that abnormalities of calcium and magnesium homeostasis could lead to increased vascular hypersensitivity, highly incriminated in the occurrence of pre-eclampsia and its complications.

In their studies Sukonpan K et al. [18], Standley CA et al. [19]., Frenkel Y et al. [20], Handwerker SM et al. [21], Hassan TJ et al. [22]. Kosch $\mathrm{M}$ et al. [23], Malas NO et al. [24], Richards SR et al. [25] note a low seric calcium and magnesium rate in pre-eclamptic pregnant compared to healthy pregnant. The results obtained from these different studies show a significant decrease of the seric magnesium and calcium in pre-eclamptic pregnant women compared to normal pregnant women, with a still very significant decrease in eclamptic pregnant. The results obtained from our study showed low levels of calcium and magnesium in pregnant women with pre-eclampsia and even more pronounced in those with eclamptic seizures. These results are similar to those obtained in many studies. However the validation of our results requires the realization of other studies on large samples. Indeed, this study took into account only four hospitals in the city of Kinshasa province with a very small effective, which is a weak point for this study.

It appears from these studies that, fluctuations in blood levels of calcium and magnesium play an important role in the pathophysiology of pre-eclampsia and its complications alongside hypoxia and are probably the determinants of the high prevalence and the seasonality of the disease in the poor regions of the globe.

Studies show that N-methyl-D-aspartate receptor stimulation in hypoxia is associated with high calcium intracellular penetration reversing the intracellular $\mathrm{Mg} / \mathrm{Ca}$ ratio, leading significant cellular alterations with the release of oxygenfree radicals, what ends to generalized endothelial dysfunction and release of some neuromediators that cause pre-eclampsia and eclampsia [8] [9] [10]. On the other hand, it has been demonstrated by in vivo and in vitro studies that hypomagnesemia and hypocalcemia are responsible for vascular spasms with elevated vascular resistance, which results in high blood pressure, a symptom major in pre-eclampsia.

Observational studies have revealed an inverse association between calcium intake and hypertensive disorders during pregnancy. Clinical trials have also confirmed that calcium supplementation reduces blood pressure and hypertensionrelated disorders. In fact, during pre-eclampsia, there are endothelial lesions that cause an increase in thromboxane A2 which is responsible for vascular spasm leading to arterial hypertension and placental ischemia. Calcium prevents this 
vasospasm, which leads to vasodilatation. A Cochrane review analysed 12 high quality trials after excluding 24 trials on supplementation of calcium to prevent pre-eclampsia in normotensive pregnant women. The dose of calcium evaluated was 1.5 to $2 \mathrm{gm}$ daily. There was less high blood pressure associated with calcium supplementation rather than placebo [26].

Magnesium competitively inhibits the binding of $\mathrm{Ca}^{2+}$ to troponin $\mathrm{C}$ in the myocyte and the formation of the calmodulin- $\mathrm{Ca}^{2+}$ complex in the smooth muscle cell preventing the occurrence of vascular spasms. At the whole heart, the negative inotropic effect of magnesium is compensated by peripheral vasodilatation and tachycardia leading to retention or even increase in cardiac output [27] [28]. Clinical studies indicate that magnesium has an anti-thrombotic property that would be beneficial in the prevention of pre-eclampsia and these complications [29]. In a Cochrane review selected randomised and quasi randomised trials of dietary magnesium supplementation during pregnancy, it showed that magnesium treatment was associated with a reduced risk of low birth weight and of small for gestational age babies compared with placebo. But, there was no apparent effect of magnesium treatment on maternal systolic or diastolic blood pressure during pregnancy [17]. However, numerous studies reveal the role of magnesium in calcium conduction whose low serum levels are implicated in the occurrence of pre-eclampsia. Extracellular magnesium inhibits also the release of noradrenaline, dopamine, acetylcholine, alters receptor sensitivity to acetylcholine and blocks the central N-methyl-D-aspartate (NMDA) receptors who are involved in the occurrence of pre eclampsia and eclampsia [10].

\section{Conclusion}

To conclude, our study shows a significant reduction of serum calcium and magnesium levels in pre-eclamptic compared to normotensive pregnant women, and establishes a relationship between the low concentration of those minerals with preeclampsia and eclampsia. Further studies should specify if low calcium and magnesium dietary intakes are determinants of the high prevalence and seasonality of the disease in our city.

\section{References}

[1] Albalas, E., Cuesta, C., Grossol, A.L., Chou, D. and Say, L. (2013) Global and Regional Estimates of Preeclampsia and Eclampsia: A Systematic Review. European Journal of Obstetrics \& Gynecology and Reproductive Biology, 170, 1-7. https://doi.org/10.1016/j.ejogrb.2013.05.005

[2] Frederick, I.O., Williams, M.A., Dashow, E., Kestin, M., Zhang, C. and Leisenring, W.M. (2005) Dietary Fiber, Potassium, Magnesium and Calcium in Relation to the Risk of Preeclampsia. The Journal of Reproductive Medicine, 50, 332-344.

[3] Villar, J., Merialdi, M., Gulmezoglu, A.M., Abalos, E., Carroli, G., Kulier, R. and de Oni, M. (2003) Nutritional Interventions during Pregnancy for Prevention or Treatment of Maternal Morbidity and Preterm Delivery: An Overview of Randomized Controlled Trials. Journal of Nutrition, 133, 1606S-1625S.

https://doi.org/10.1093/jn/133.5.1606S 
[4] Subramanian, V. (2007) Seasonal Variation in the Occurrence of Preeclampsia and Eclampsia in Tropical Climatic Conditions. BMC Women's Health, 7, 18. https://doi.org/10.1186/1472-6874-7-18

[5] Yackerson, N.S., Pius, B. And Friger, M. (2007) The Influence of Weather Stade on the Incidence of Preeclampsia and Placental Abruption in Semi-Arid Areas. Clinical and Experimental Obstetrics \& Gynecology, 34, 27-30.

[6] Dieckmann, W.J. (1938) The Geographic Distribution and Effect of Climate on Eclampsia, Toxaemia of Pregnancy, Hyperemesis Gravidarum, and Abruption Placentae. American Journal of Obstetrics \& Gynecology, 36, 623-631. https://doi.org/10.1016/S0002-9378(38)90532-0

[7] Qiu, C., Coughlin, K.B., Fredekick, I.O., Sorensen, T.K. and Williams, M.A. (2008) Dietary Fiber Intake in Early Pregnancy and Risk of Subsequent Preeclampsia. American Journal of Hypertension, 21, 903-909. https://doi.org/10.1038/ajh.2008.209

[8] Indumati, K., Kodliwadmath, M.V. and Sheela, M.K. (2011) The Role Serum Electrolytes in Pregnancy Induced Hyprtension. Journal of Clinical and Diagnostic Research, 5, 66-69.

[9] Hamet, P. (1995) The Evaluation of the Scientific Evidence for a Relationship between Calcium and Hypertension. Journal of Nutrition, 125, 311S-400S.

[10] Touyz, R.M. (2003) Role of Magnesium in the Pathogenesis of Hypertension. Mol Aspects Med, 24, 107-136. https://doi.org/10.1016/S0098-2997(02)00094-8

[11] Elongi, M.J.P., Tandu, U., Spitz, B. and Verdonck, F. (2011) Influence de la variation saisonnière sur la prévalence de la pré éclampsie à Kinshasa. Gynécologie $O b$ stétrique et Fertilité, 39, 132-135. https://doi.org/10.1016/j.gyobfe.2010.12.010

[12] (2001) Report of the National High Blood Pressure Education Program Working Group on High Blood Pressure in Pregnancy. American Journal of Obstetrics \& Gynecology, 185, 522-523.

[13] Akinloye, O., Oyewale, O.J. and Oguntibeju, O.O. (2010) Evaluation of Trace Elements in Pregnant Women with Pre-Eclampsia. African Journal of Biotechnology, 9, 5196-5202.

[14] Jain, S., Sharma, P., Kulshreshtha, S., Mohan, G. and Singh, S. (2010) The Role of Calcium, Magnesium and Zinc in Preeclampsia. Biological Trace Element Research, 133, 162-170. https://doi.org/10.1007/s12011-009-8423-9

[15] Roberts, J.M., Balk, J.L., Bodnar, L.M., Belizan, J.M., Bergel, E. and Martinez, A. (2003) Nutrient Involvement in Preeclampsia. The Journal of Nutrition, 133, 16841692. https://doi.org/10.1093/jn/133.5.1684S

[16] Punthumapol, C. and Kittichotpanich, B. (2008) Serum Calcium, Magnesium and Uric Acid in Preeclampsia and Normal Pregnancy. Journal of the Medical Association of Thailand, 91, 968-973.

[17] Makrides, M. and Crowther, C.A. (2012) Magnesium Supplementation in Pregnancy (Review). The Cochrane Database of Systematic Reviews, 10, CD000937.

[18] Sukonpan, K. and Phupong, V. (2005) Serum Calcium and Serum Magnesium in Normal and Preeclamptic Pregnancy. Archives of Gynecology and Obstetrics, 273, 12-16. https://doi.org/10.1007/s00404-004-0672-4

[19] Standley, C.A., Whitty, J.E., Mason, B.A. and Cotton, D.B. (1997) Serum Ionized Magnesium Levels in Normal and Preeclamptic Gestation. Obstetrics \& Gynecology, 89, 24-27. https://doi.org/10.1016/S0029-7844(96)00380-8

[20] Frenkel, Y., Weiss, M., Shefi, M., Lusky, A., Mashiach, S. and Dolev, E. (1994) 
Mononuclear Cell Magnesium Content Remains Unchanged in Various Hypertensive Disorders of Pregnancy. Obstetrics \& Gynecology, 38, 220-222. https://doi.org/10.1159/000292485

[21] Handwerker, S.M., Altura, B.T. and Altura, B.M. (1997) Serum Ionized Magnesium Levels in Normal and Preeclamptic Gestation. Obstetrics \& Gynecology, 89, 1051-1052. https://doi.org/10.1016/S0029-7844(97)80058-0

[22] Hassan, T.J., Sadaruddin, A. and Jafarey, S.N. (1991) Serum Calcium, Urea and Uric Acid Levels in Pre-Eclampsia. Journal of the Pakistan Medical Association, 41, 183-185.

[23] Kosch, M., Hausberg, M., Louwen, F., Barenbrock, M., Rahn, K.H. and Kisters, K. (2000) Alterations of Plasma Calcium and Intracellular and Membrane Calcium in Erythrocytes of Patients with Pre-Eclampsia. Journal of Human Hypertension, 14, 333-336. https://doi.org/10.1038/sj.jhh.1001006

[24] Malas, N.O. and Shurideh, Z.M. (2001) Does Serum Calcium in Pre-Eclampsia and Normal Pregnancy Differ? Saudi Medical Journal, 22, 868-871.

[25] Richards, S.R., Nelson, D.M. and Zuspan, F.P. (1984) Calcium Levels in Normal and Hypertensive Pregnant Patients. American Journal of Obstetrics \& Gynecology, 149, 168-171. https://doi.org/10.1016/0002-9378(84)90191-1

[26] Hofmeyr, G.J., Duley, L. and Atallah, A.N. (2010) Calcium Supplementation during Pregnancy for Preventing Hypertensive Disorders and Related Problems. The Cochrane Database of Systematic Reviews, 8, CD001059. https://doi.org/10.1002/14651858.CD001059.pub3

[27] Boschat, J., Gilard, M., Etienne, Y., Roriz, R., Jobic, Y., Penther, P., et al. (1989) Effets hémodynamiques du sulfate de magnésium intraveineux chez l'homme. Archives Des Maladies Du Coeur Et Des Vaisseaux, 82, 361-364.

[28] Vigorito, C., Giordano, A., Ferraro, P., Acanfora, D., De Caprio, L., Naddeo, C., et al. (1991) Hemodynamic Effets of Magnesium Sulfate on the Normal Human Heart. American Journal of Cardiology, 67, 1435-1437. https://doi.org/10.1016/0002-9149(91)90478-4

[29] Shechter, M., Merz, C.N., et al. (1999) Oral Magnesium Supplementation Inhibits Platelet-Dependent Thrombosis in Patients with Coronary Disease. American Journal of Cardiology, 84, 152-156. https://doi.org/10.1016/S0002-9149(99)00225-8 